\title{
Development of a Novel Alarm System to Improve Adaptation to Non-invasive Ventilation in Patients With High Cervical Spinal Cord Injury

\author{
Sang Hun Kim, $\mathrm{MD}^{1}$, Yong Beom Shin, $\mathrm{MD}$, $\mathrm{PhD}^{1}$, Myung Hun Jang, $\mathrm{MD}^{1}$, \\ Soo-Yeon Kim, MD, $\mathrm{PhD}^{2}$, Jung Hoon Ro, $\mathrm{PhD}^{3}$
}

\begin{abstract}
${ }^{1}$ Department of Rehabilitation Medicine, Pusan National University Hospital, Pusan National University School of Medicine, Busan; ${ }^{2}$ Department of Rehabilitation Medicine, Pusan National University Yangsan Hospital, Pusan National University School of

Medicine, Yangsan; ${ }^{3}$ Department of Biomedical Engineering, Pusan National University School of Medicine, Busan, Korea
\end{abstract}

In this case report, we want to introduce a successful way of applying non-invasive ventilation (NIV) with a full face mask in patients with high cervical spinal cord injury through a novel alarm system for communication. A 57-year-old man was diagnosed with C3 American Spinal Injury Association impairment scale (AIS) B. We applied NIV for treatment of hypercapnia. Because of mouth opening during sleep, a full face mask was the only way to use NIV. However, he could not take off the mask by himself, and this situation caused great fear. To solve this problem, we designed a novel alarm system. The best intended motion of the patient was neck rotation. Sensing was performed by a balloon sensor placed under the head of the patient. A beep sound was generated whenever the pressure was above the threshold, and more than three consecutive beeps within 3,000 ms created a loud alarm for caregivers.

Keywords Noninvasive ventilation, Spinal cord injuries, Hypercapnia

\section{INTRODUCTION}

Spinal cord injury (SCI) causes motor and sensory impairment below the neurological level of injury. SCI also leads to respiratory failure due to complete or incomplete paralysis of numerous respiratory muscles. In the case of cervical or thoracic SCI, disruption of the descending bulbospinal respiratory pathway from the central nervous system to respiratory muscles presents distinguishing respiratory patterns which are associated with

Received February 11, 2016; Accepted April 22, 2016

Corresponding author: Yong Beom Shin

Department of Rehabilitation Medicine, Pusan National University Hospital, Pusan National University School of Medicine, 179 Gudeok-ro, Seo-gu, Busan 49241, Korea. Tel: +82-51-240-7485, Fax: +82-51-247-7485, E-mail: yi0314@gmail.com

ORCID: Sang Hun Kim (http://orcid.org/0000-0003-4849-5228); Yong Beom Shin (http://orcid.org/0000-0001-5026-1696); Myung Hun Jang (http:// orcid.org/0000-0002-9694-5409); Soo-Yeon Kim (http://orcid.org/0000-0001-5679-0126); Jung Hoon Ro (http://orcid.org/0000-0002-5203-5956).

(c) This is an open-access article distributed under the terms of the Creative Commons Attribution Non-Commercial License (http://creativecommons.org/ licenses/by-nc/4.0) which permits unrestricted noncommercial use, distribution, and reproduction in any medium, provided the original work is properly cited. Copyright (c) 2016 by Korean Academy of Rehabilitation Medicine 
the neurological level of injury, duration and severity [1]. Accompanying diaphragmatic paralysis is often found in patients with SCI above the C6 level. Consequently, mechanical ventilatory support may be required in high cervical SCI, and difficulty in weaning from mechanical ventilation is proportional to the level and severity of SCI [2].

Although it is difficult to obtain patient cooperation, non-invasive ventilation (NIV) is frequently selected as the best choice for treatment of respiratory failure in patients with SCI. However, most of the patients with tetraplegia cannot take off the mask by themselves. Therefore, the caregiver is unable to communicate with the patient wearing a full face mask when the patient needs help. In the following case report, we want to introduce a successful way of applying NIV with a full face mask in patients with high cervical SCI through a novel alarm system for communication.

\section{CASE REPORT}

A 57-year-old man had an industrial accident in August 2009. He was diagnosed with a $\mathrm{C} 2$ vertebral body fracture and high cervical SCI at the C3 level. On physical examination, he did not have key muscle activity in all extremities and the last intact sensory level was the C3 dermatome. He felt deep anal pressure but he did not have voluntary anal contraction. According to the International Standards for Neurological Classification of Spinal Cord Injury (ISNCSCI), he was classified as C3 AIS B (American Spinal Injury Association impairment scale B). In February 2010, he had his pulmonary function tested for the first time and his pulmonary function was severely decreased. The tidal volume, vital capacity, and peak cough flow were $220 \mathrm{~mL}, 800 \mathrm{~mL}$, and $130 \mathrm{~L} / \mathrm{min}$ in the supine position, respectively. Continuous hypercapnia, defined as partial pressure of carbon dioxide in arterial blood $\left(\mathrm{PaCO}_{2}\right)$ of over $45 \mathrm{mmHg}$, was also recorded. In the diaphragm fluoroscopy, the average length of the diaphragm apex was decreased on both sides up to 10 and $15 \mathrm{~mm}$ during tidal breathing and 20 and $40 \mathrm{~mm}$ during deep breathing [3]. We initially applied a portable ventilator with volume controlled assisted ventilation mode. Respiratory function gradually improved through active pulmonary rehabilitation techniques such as air stacking exercise with an Ambu bag and sputum expectoration by mechanical insufflation-exsufflation and accessory respiratory muscle training. However, he was readmitted to the intensive care unit due to septic shock caused by urinary tract infection one year after the last discharge from the hospital. Unfortunately, a tracheostomy was performed again, and then the step-by-step pulmonary rehabilitation program was prescribed, as mentioned above. Although we could remove the tracheostomy tube, total weaning did not take into account respiratory insufficiency in SCI, concomitant sleep apnea and the aging. We applied an intermittent NIV with pressure support ventilation mode during the night time to solve the problem of hypercapnia. Initially, we used a nasal mask but he could not adjust to the mask due to mouth opening during sleep (Fig. 1). Then, we applied a full face mask, which can cover the nose and mouth at the same time, for reducing oral air leak. However, he could not take off the mask by himself, which blocked his voice, and this situation caused great fear. Because the main problem was a limitation of communication, we focused on the key motion which the patient could make for developing a solution.

We designed a novel alarm system after discussion with the Department of Biomedical Engineering. The system consisted of a microcontroller board (Arduino UNO; Arduino, Somerville, MA, USA) which is an open source electronics platform based on an easy-to-use hardware and a sound generator, a pressure transducer using an

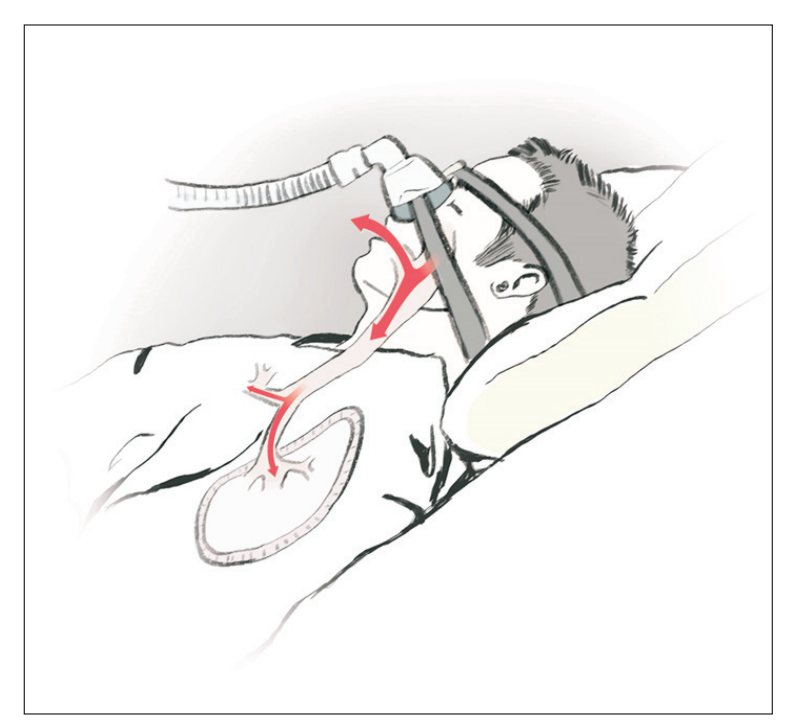

Fig. 1. Air leakage through the mouth during nasal mask ventilation. 
existing endotracheal tube (Fig. 2). The system had been programmed with the open-source software (Arduino software). The best clear and easy intended motion of the patient was neck rotation. Sensing of the intended motion was performed by a balloon of the endotracheal tube placed under the pillow or head of the patient (Fig. $3)$. The sensor reacted only when the pressure exceeded $10 \mathrm{~cm} \mathrm{H}_{2} \mathrm{O}$. In this setting, the sensor ignored unnecessary signals such as a smooth ascending pressure or an unintended pressure below this threshold value. If the pressure exceeded $10 \mathrm{~cm} \mathrm{H}_{2} \mathrm{O}$, an intended neck rotation by the patient provoked a single beep sound made by the sound generator for the patient. More than three consecutive beeps within $3,000 \mathrm{~ms}$ created a loud alarm sound through speakers for the nurse or caregiver.

After applying this pressure alarm system, he could easily adapt to the full face mask without anxiety and was discharged home without any complications.

\section{DISCUSSION}

Respiratory muscle stiffness, low lung compliance, and decreased cough ability are the reasons for inadequate clearance of the secretion, thereby increasing the risk of respiratory complications in patients with SCI [4]. Unfortunately, prolonged mechanical ventilation is directly correlated with respiratory complications, which are the major causes of mortality in high cervical SCI [5]. After considering the above results, pulmonary rehabilitation should be considered as important as functional rehabilitation of SCI. Numerous verified respiratory muscle training programs have been prescribed recently in many rehabilitation centers [6]. Before starting the training program, proper evaluation and analysis of the pulmonary function parameters in patients with SCI are crucial. Through a series of evaluation, we can determine whether to apply a mechanical ventilator. Mechanical ventilation via tracheostomy is helpful in acute or severe condi-
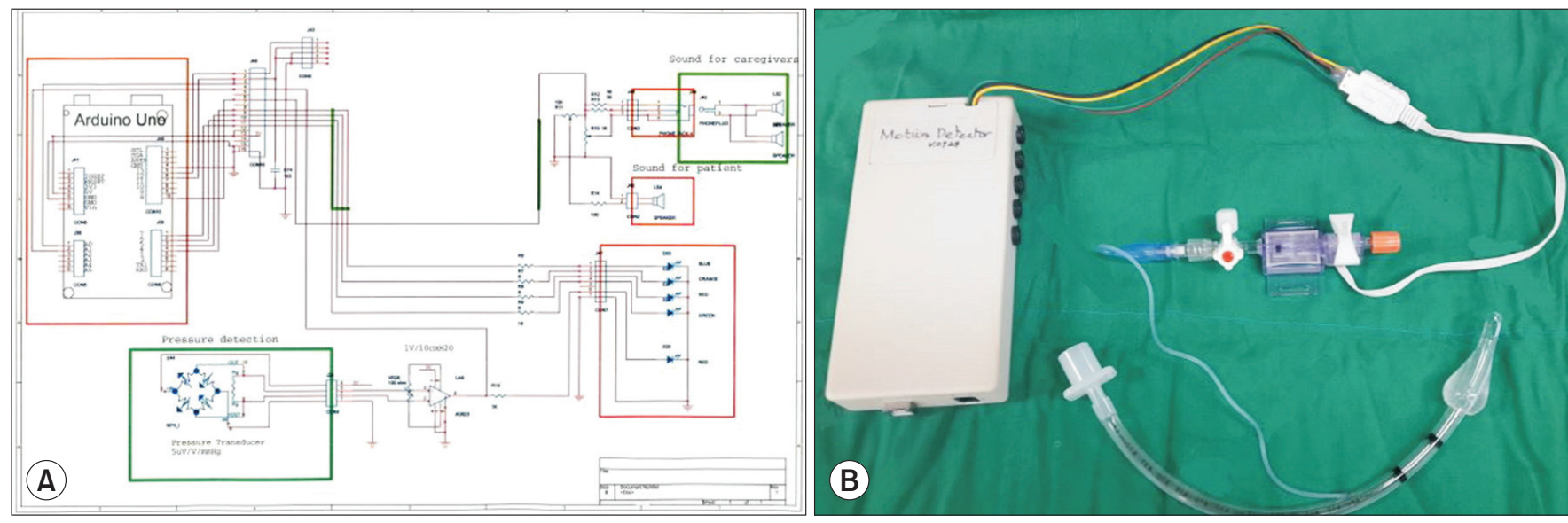

Fig. 2. The alarm system. (A) A schematic diagram of the alarm system. (B) An actual photograph of the components.
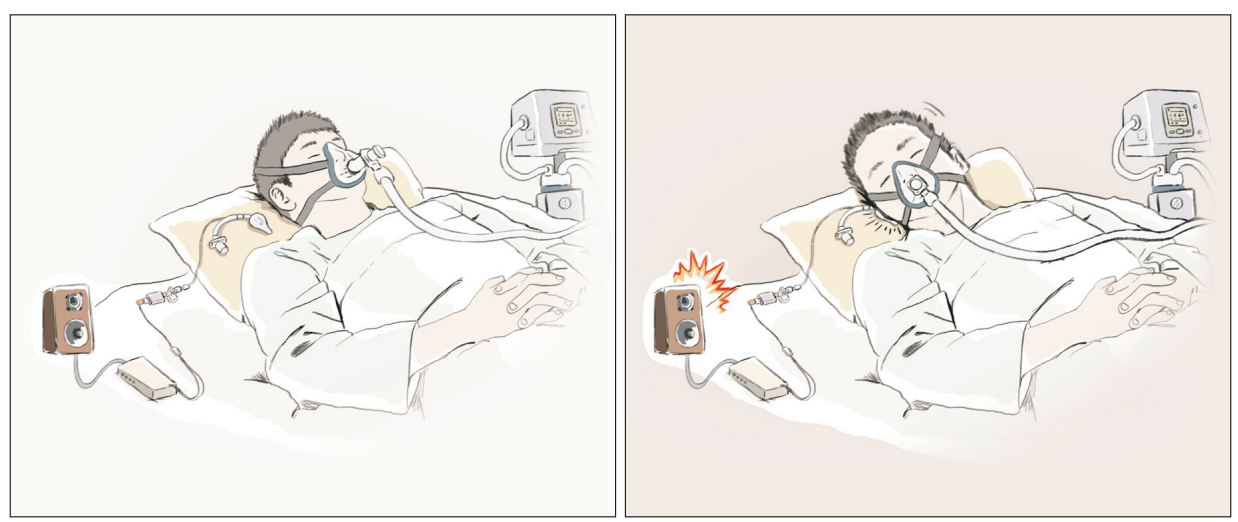

Fig. 3. The alarm system which detects the intended neck rotation motion by the pressure variation of a balloon placed under the head of the patient during full face mask ventilation. 
tions. If patients can effectively clear the sputum, NIV has some clinical benefits than tracheostomy. Among the benefits, a possibility of self-vocalization can provide a better quality of life to the patients. While the patient uses NIV, a nasal mask is more favorable for vocalization than a full face mask. However, some limitations of a nasal mask, including anxiety, oral air leakage, and poor fit, can cause low patient adherence [7]. For these reasons, we need to carefully determine the best decision.

In this case, there were main problems such as anxiety and limited communication caused by use of the full face mask in a patient with high cervical SCI. Although we did not prescribe any antidepressant or antipsychotic drugs for the treatment of anxiety, the new alarm system was successful in solving these problems.

Environmental control system (ECS) is a type of assistive technology that helps the disabled. ECS consists of processing controller, switches and mounting options. In some developed countries, ECS is already being widely used in tetraplegic patients with SCI or neuromuscular diseases [8]. Based on the patient's condition, a tetraplegic patient can control the devices by his/her breath, EEG signal, EMG signal or intact movement. Our alarm system can also be included in an ECS switch unit for nurse calling. Other existing nurse call devices have several limitations in our patient. For example, a breath call device cannot be used during NIV with a full face mask. EEG and EMG switch devices are complicated and expensive. A pillow switch call system similar to our device can cause unintended alarm sounds due to a sensitive sensor and simple method of operation. Our alarm device improved upon these limitations. Moreover, we used an endotracheal tube, a common medical device, as a balloon sensor. If there is a problem with the sensor, the patient can easily replace it at a low cost.

Recently, technological convergence has been adopted as a national developmental strategy and healthcare market is undergoing rapid growth. Therefore, we need to consider sharing our clinical experience in rehabilitation medicine with another team such as biomedical engineering. Consequently, we will gradually be in a position to give our advice for the development of a new ECS. A more individualized ECS will improve the quality of life of various patients.

\section{CONFLICT OF INTEREST}

No potential conflict of interest relevant to this article was reported.

\section{ACKNOWLEDGMENTS}

This work was supported by clinical research grant from Pusan National University Hospital in 2016.

\section{REFERENCES}

1. Terson de Paleville DG, McKay WB, Folz RJ, Ovechkin AV. Respiratory motor control disrupted by spinal cord injury: mechanisms, evaluation, and restoration. Transl Stroke Res 2011;2:463-73.

2. Como JJ, Sutton ER, McCunn M, Dutton RP, Johnson $\mathrm{SB}$, Aarabi B, et al. Characterizing the need for mechanical ventilation following cervical spinal cord injury with neurologic deficit. J Trauma 2005;59:912-6.

3. Boussuges A, Gole Y, Blanc P. Diaphragmatic motion studied by m-mode ultrasonography: methods, reproducibility, and normal values. Chest 2009;135:391400.

4. Kang SW, Shin JC, Park CI, Moon JH, Rha DW, Cho DH. Relationship between inspiratory muscle strength and cough capacity in cervical spinal cord injured patients. Spinal Cord 2006;44:242-8.

5. Ball PA. Critical care of spinal cord injury. Spine (Phila Pa 1976) 2001;26(24 Suppl):S27-30.

6. Berlowitz DJ, Tamplin J. Respiratory muscle training for cervical spinal cord injury. Cochrane Database Syst Rev 2013;7:CD008507.

7. Garuti G, Nicolini A, Grecchi B, Lusuardi M, Winck JC, Bach JR. Open circuit mouthpiece ventilation: concise clinical review. Rev Port Pneumol 2014;20:211-8.

8. Verdonck MC. The meaning of environmental control systems (ECS) for people with spinal cord injury: an occupational therapist explores an intervention [dissertation]. Cork: University College Cork; 2012. 